Running head: ANGER, HOSTILITY, AND PTSD

Anger, Hostility, and Posttraumatic Stress Disorder in Trauma-Exposed Adults: A Meta-Analysis

\author{
Ulrich Orth and Elias Wieland
}

University of Berne

\begin{abstract}
(C) American Psychological Association. This article has been accepted for publication but has not been through the copyediting, typesetting, pagination, and proofreading process. This article may not exactly replicate the final, authoritative version published in the journal. It is not the copy of record. Please cite this article as follows:

Orth, U., \& Wieland, E. (2006). Anger, hostility, and posttraumatic stress disorder in trauma-exposed adults: A meta-analysis. Journal of Consulting and Clinical Psychology, 74, 698-706. http://dx.doi.org/10.1037/0022-006X.74.4.698
\end{abstract}

\title{
Ulrich Orth
}

Department of Psychology

University of Berne

Muesmattstrasse 45

3012 Berne

Switzerland

ulrich.orth@psy.unibe.ch

Tel +41316314043

Fax +41316318212 


\begin{abstract}
This meta-analysis synthesizes the available data on the strength of association between anger and posttraumatic stress disorder (PTSD), and hostility and PTSD, covering 39 studies with trauma-exposed adults. Effect sizes did not differ for anger and hostility, which could therefore be combined; effect sizes for anger expression variables were analyzed separately. The analyses revealed large effects. The weighted mean effect size was $r=.48$ for anger/hostility, $r=.29$ for anger out, $r=.53$ for anger in, and $r=-.44$ for anger control. Moderator analyses were conducted for anger/hostility, showing that effect sizes are substantially larger with increasing time since the event, and that effect sizes are larger in samples with military war experience than in samples with other types of traumatic events.
\end{abstract}

Key Words: posttraumatic stress disorder, anger, hostility 
Anger, Hostility, and Posttraumatic Stress Disorder in Trauma-Exposed Adults: A Meta-Analysis Common stereotypes portray traumatized individuals as individuals full of fear and helplessness but not full of anger and hostility. Indeed, for a long time, theories of posttraumatic stress disorder (PTSD) focused on fear as the central emotion in the disorder and did not consider anger and hostility to be central attributes of individuals suffering from PTSD (cf. Brewin \& Holmes, 2003). Consequently, empirical studies investigating anger and hostility in PTSD were sparse.

However, the definition of posttraumatic stress disorder (PTSD) of the Diagnostic and Statistical Manual of Mental Disorders (DSM-III-R, American Psychiatric Association, 1987; DSM-IV, American Psychiatric Association, 1994) lists irritability and outbursts of anger as one of the hyperarousal symptoms. Moreover, Novaco and Chemtob (1998) point out in their review on anger and PTSD that in fact early observations showed anger to be a prevalent component of posttraumatic stress reactions, particularly in veterans with combat experience. For about the last decade now, an increasing number of studies have explicitly focused on anger in individuals with PTSD (e.g., Chemtob, Hamada, Roitblat, \& Muraoka, 1994; Frueh, Henning, Pellegrin, \& Chobot, 1997; Riggs, Dancu, Gershuny, Greenberg, \& Foa, 1992; Schützwohl \& Maercker, 2000). Taken together, the results of these studies suggest that anger is substantially associated with PTSD severity. Therefore, we decided to summarize the available data on the strength of association between anger and PTSD by means of a meta-analysis.

Importantly, Novaco and Chemtob (2002) looked at whether the correlation between anger and PTSD is artificially inflated by the fact that anger is one of the diagnostic criteria for PTSD. However, they found that the correlation did not substantially decrease when items measuring anger and irritability within PTSD scales were removed. Orth, Cahill, Foa, and Maercker (submitted) investigated this issue in another sample, consisting of female crime 
victims and four repeated assessments of PTSD and anger. The results showed that the correlations likewise did not substantially decrease (from .38 to .36 for Time 1, from .39 to .36 for Time 2, from .51 to .49 for Time 3, and from .42 to .41 for Time 4$)$. Thus, the results of both studies indicate that the correlation between PTSD and anger is not a methodological artifact.

The question, then, is which psychological processes cause anger to be related with PTSD symptomatology? One theory explaining the relation between anger and PTSD, which can be labeled survival mode theory, was formulated by Chemtob, Novaco, and colleagues (cf. Chemtob, Novaco, Hamada, Gross, \& Smith, 1997; Novaco \& Chemtob, 1998). They hypothesize that individuals suffering from PTSD have a substantially lowered threshold to perceiving situations as threatening, and that the perception of threat activates a biologically predisposed survival mode, including fear and flight reactions as well as anger and fight reactions. Another theory explaining the relation between anger and PTSD, which can be labeled fear avoidance theory, was introduced by Foa and colleagues (Feeny, Zoellner, \& Foa, 2000; Foa, Riggs, Masie, \& Yarczower, 1995; Riggs et al., 1992). They hypothesize that individuals with PTSD are motivated to avoid trauma-related feelings of fear, which are activated by posttraumatic intrusions, and that trauma-related anger serves as a welcome focus of attention because anger is an emotion with a more positive emotional valence than fear.

The theories described above focus on anger and PTSD, but not on hostility. However, the concepts of anger and hostility are closely linked to each other. Anger is understood as an emotion, and defined by its characteristic cognitive, physiological, motivational and behavioral components (cf. Berkowitz, 1999; Izard, 1991). In particular, the cognitive component involves the perception that important personal goals are blocked by improper action of an external agent, and the motivational component frequently involves hostile and aggressive impulses. On the other hand, hostility is understood as an attitudinal construct, and defined as a predisposition to 
dislike and mistrust others, and to interpret their behavior as egoistic and hurtful (cf. Miller, Smith, Turner, Guijarro, \& Hallet, 1996). As a consequence, hostility causes an increased frequency of anger and aggression. Thus, anger and hostility may reciprocally activate each other and motivate the individual to aggressive behavior against others.

Measures of anger and hostility frequently contain overlapping content. For example, the Buss-Durkee Hostility Inventory (BDHI; Buss \& Durkee, 1957) comprises in its revised form (Aggression Questionnaire; Buss \& Perry, 1992) four scales measuring anger, hostility, verbal aggression, and physical aggression, indicating that the BDHI measures not only an attitudinal construct but also the related affective and behavioral constructs anger and aggression. The Cook-Medley Hostility Inventory (Cook \& Medley, 1954) measures affective and behavioral components besides hostility (Eckhardt, Norlander, \& Deffenbacher, 2004). As a last example, the hostility scale of the Symptom Checklist SCL-90 (Derogatis, Lipman, \& Covi, 1973; Derogatis \& Savitz, 1999) also contains items that measure anger. Therefore, it is no surprise that measures of anger and hostility are often strongly correlated (cf. Eckhardt et al., 2004).

Given the strong conceptual and empirical links between anger and hostility, we decided to include both anger and hostility in the meta-analysis and to test whether using a combined effect size for anger and hostility is justified. A combined effect size would have the advantage of greater reliability (because of a larger number of studies) and greater generalizability (because results are valid for both anger and hostility). To combine the effect sizes two conditions have to be fulfilled: the effect sizes have to be strongly correlated, and the mean effect sizes have to be at the same level.

The first goal of the meta-analysis was to determine the strength of association between anger and PTSD, and hostility and PTSD, respectively, in trauma-exposed adults. Some of the frequently used measurement instruments of anger comprise, beside measures of anger intensity 
or frequency, measures of anger expression styles, i.e. anger out (expression of anger in verbal or physically aggressive behavior toward others or objects), anger in (inhibition and suppression of anger), and anger control (control of the experience and expression of anger). Effect sizes for these variables provide additional information, which might be useful in future theorizing about the relation between anger and PTSD. Therefore, we decided to include anger expression variables in the meta-analysis.

The second goal of the meta-analysis was to test potential moderators of the relation between anger, hostility, and PTSD. We hypothesized that type of event and time since event should be important moderators of the relation for reasons outlined below. In addition, we included mean age and gender in the analysis for exploratory reasons, because age and gender are basic sample characteristics taken into account in meta-analyses as a matter of standard.

However, we did not have hypotheses why age and gender should moderate the relation between anger and PTSD, or hostility and PTSD, respectively.

A first important moderator might be the type of traumatic event. Anger as an important topic in PTSD emerged primarily in studies with Vietnam War veterans (e.g., Beckham et al., 1996; Chemtob et al., 1994; Frueh et al., 1997; Lasko, Gurvits, Kuhne, Orr, \& Pitman, 1994), which might indicate that anger is a particularly salient problem in veterans suffering from PTSD. Therefore, we tested whether samples with military war experience show a particularly strong relation between anger and PTSD, and hostility and PTSD, respectively. A potential factor is that individuals selected for military service might have substantially higher assertiveness, aggressiveness, and trait anger even before a traumatic event.

A second important moderator might be the time since the event. Interestingly, the few longitudinal studies that repeatedly measured both anger and PTSD suggest that the correlation between anger and PTSD becomes stronger with increasing time since the event. For example, in 
the study of Feeny et al. (2000) the correlation increased from $r=.07$ after two weeks to $r=.21$ after four weeks to $r=.38$ after twelve weeks. In the study by Ehlers, Mayou, and Bryant (1998) the correlation between anger and PTSD was $r=.37$ after three months and $r=.47$ after one year. Theories of associative networks in memory (cf. Bower, 1981) might provide an explanation for the time-dependent increase of the correlation. At the beginning, the association between fear and anger structures might be weak, but repeated simultaneous activation of the memory structures should increasingly strengthen the association. We hypothesized that the relation between the effect size (correlation of anger and PTSD, or hostility and PTSD, respectively) and time since event does not follow a linear function but, rather, a logarithmic function, because under the assumption of stationary causal processes (i.e., stable causal effects) the correlation between two variables initially increases after the onset of the causal processes (i.e., the traumatic event) and then reaches equilibrium over time (i.e., converges to a fixed value; Cole \& Maxwell, 2003). Indeed, a longitudinal study of anger and PTSD showed that the assumption of stationary causal processes is empirically justified (Orth et al., submitted).

\section{Method}

\section{Selection of Studies}

English-language journal articles, books, and book chapters were searched in the computerized databases PsycInfo, Medline, and the PILOTS database produced by the National Center for PTSD for all years covered in the databases through 2003. We did not search for dissertations or unpublished reports, as our later analyses strongly suggested that no publication bias exists (see results section). We used the following search terms: anger, hostility, PTSD, traumatic stress, posttraumatic stress (thus including posttraumatic stress disorder and posttraumatic stress reactions). In PsycInfo, we additionally searched for traumatic neurosis and stress reactions in the entries before 1985, as recommended in the database. The assessment of 
the abstracts yielded 189 potentially relevant articles. These articles were then assessed in full text by both authors of this meta-analysis. The interrater agreement on inclusion or exclusion in the meta-analysis was high with $\kappa=.95$ and all differing assessments were discussed until we reached consensus.

Studies were included in the meta-analysis if the following criteria were fulfilled: (a) all participants of the sample were trauma-exposed, i.e., they experienced a traumatic event as defined by the diagnostic criterion A1 of the DSM-IV (American Psychiatric Association, 1994); if the sample comprised non-trauma-exposed participants and if it was possible to restrict the effect size computation to the trauma-exposed subsample, we included the study in the metaanalysis and the values of sample characteristics were computed only for the trauma-exposed subsample; (b) anger variables or hostility variables were assessed; relevant anger measures were trait and state measures of anger, as well as the anger expression variables anger out, anger in, and anger control, as measured, e.g., by the State-Trait Anger Expression Inventory, STAXI (Spielberger, Sydeman, Owen, \& Marsh, 1999); (c) PTSD diagnosis or severity of posttraumatic stress reactions was assessed; (d) enough information was given to compute an effect size; (e) at the time of measurement, participants were 16 years or older.

If a sample was analyzed by more than one study, only one study was included in the meta-analysis to ensure independence of effect sizes. In these cases, we included the study that provided the most comprehensive coding information (e.g., the highest number of anger and hostility measures) and excluded the other studies. To the best of our knowledge, the following samples were analyzed by more than one study: the sample of Calhoun, Beckham, Feldman et al. (2002), which we included, was also used by Beckham, Feldman, Kirby, Hertzberg, and Moore (1997), Beckham et al. (1996), Beckham et al. (2002), and Calhoun, Beckham, and Bosworth 
(2002), which we excluded; the sample of Ehlers et al. (1998), which we included, was also used by Mayou, Ehlers, and Bryant (2002), which we excluded; the sample of Feeny et al. (2000), which we included, was also used by Zoellner, Foa, and Brigidi (1999), which we excluded; and the sample of Z. Solomon, Mikulincer, and Bleich (1988), which we included, was also used by Z. Solomon (1989), which we excluded.

Studies were also excluded if anger/hostility and PTSD were not assessed at the same time point, because our aim was to investigate the cross-sectional association between the variables. For this reason, we excluded the study of Riggs et al. (1992), where anger was assessed one week after the event, but PTSD was assessed one month after the event.

Finally, studies were also excluded if conflicting information needed for the computation of effect sizes was given in, e.g., text, abstract, tables, or figures. For this reason, we excluded the studies by Ford, Fisher, and Larson (1997), Hyer et al. (1986), and Roberts et al. (1982).

This procedure left 38 articles for analysis. All studies were published as journal articles, none as books or book chapters. The article of Hovens, Bramsen, and van der Ploeg (2002) provided two relevant samples; thus, our data set comprised $k=39$ studies.

\section{Coding of Studies}

We coded the following data: sample size, country of origin, mean age of participants, proportion of female participants, type of traumatic event (criminal victimization incl. rape, military war experience, civilian war experience, technological disaster, natural disaster, health trauma, witnessing a traumatic event or being confronted with the traumatic event of a significant other, mixed), mean time since event, measures of anger and hostility, measures of PTSD, effect sizes. Effect sizes were coded separately for 5 variables (anger, anger out, anger in, anger control, hostility). 
Unfortunately, mean time since event was not reported in 22 of 39 studies. However, in 18 of these 22 studies, the event was clearly indicated in the text (e.g., Vietnam War), reporting exclusively on samples with military war experience. Thus, data were not missing at random, but missingness of data was substantially confounded with type of event, and, consequently, with the variable for which data were missing itself (the average time since event was supposably much larger for samples with military war experience compared to the remaining samples). However, if data are not missing at random and if the number of missings is not negligible, all procedures to deal with missing data such as case deletion or missing data imputation yield significantly biased results (cf. Schafer \& Graham, 2002). The only alternative allowing for an analysis of the variable was to estimate time since event based on information explicitly given in the study, using the following procedure which we judged as highly valid. Assuming that studies were published on average three years after data collection, we estimated time since event as difference between year of data collection (year of the earliest publication with the sample minus three, if not otherwise indicated in the text) and year of event. If the event covered more than one year (e.g., Vietnam War), we took the end of the event as reference year (e.g., 1975) to prevent overestimation (other reference years were: 1945 for World War II and 1953 for the Korean War). The interrater agreement, based on codings by both authors of this meta-analysis, was high with $r=1.00$ for this variable.

Effect sizes were coded in the form of zero-order correlations ( $r$-type). If effect sizes had to be computed from summary statistics (means, standard deviations, frequencies, etc.), we used the Effect Size Determination Program by Daniel B. Wilson (cf. Lipsey \& Wilson, 2001, Appendix C). If effect sizes were computable for more than one measurement time, we coded the data of the first time because these measures should be least influenced by the study design. If a study provided more than one effect size (because, e.g., two or more hostility measures were 
used), we averaged the correlations using Fisher's $Z_{r}$ transformations. In contrast, if effect sizes were computable for the relation with the dichotomous version of a variable (e.g., PTSD diagnosis) as well as with the continuous version of the same variable (e.g., PTSD symptom severity), we used only the effect sizes based on the continuous version because of higher precision.

All studies were coded by both authors of this meta-analysis. The interrater agreement was high ( $\kappa \geq .85$ for categorical variables and $r \geq .97$ for continuous variables). All differing codings were discussed until we reached consensus.

\section{Meta-Analytic Procedure}

All computations with effect sizes were made using Fisher's $Z_{r}$ transformations and using study weights with $\omega=n-3$ (cf. Lipsey \& Wilson, 2001). For the computations we used SPSS and the SPSS Macros written by Daniel B. Wilson (cf. Lipsey \& Wilson, 2001, Appendix D).

We conducted the following preliminary analyses. First, we searched for statistical outliers on effect size variables. Second, we determined whether we could use an effect size measure combining the effect sizes for anger and hostility. Third, we determined whether there is evidence of publication bias or not, i.e., whether studies with non-significant findings had a lower probability of being published. To test for publication bias we followed the recommendations of Begg (1994). If publication bias exists, studies resulting in low effect sizes should have a low probability of being published if the sample size is small (because of low probability of significant findings). In contrast, studies resulting in large effect sizes have a high probability of being published even if sample size is small (because of high probability of significant findings). The relationship of sample size and effect size may be visually examined using a funnel graph (cf. Begg, 1994). If the funnel graph does not show a symmetric shape, and if studies with small 
sample size show a bias towards larger effect sizes, there is evidence for publication bias. In this case, we would have to include dissertations and unpublished reports in the meta-analysis and return to the steps of selection of studies and coding of studies. Comparison of effect sizes for published and unpublished studies could then reveal the magnitude of the publication bias. However, if there is no evidence for publication bias, we can continue with the meta-analysis without consideration of dissertations and unpublished reports.

In the effect size analyses, we used a fixed effects as well as a random effects model. If the results of the fixed effects model show that the homogeneity statistics are not significant, a fixed effects model is appropriate, providing the advantage of a smaller confidence interval for the mean effect size. In this case, we will report effect size statistics as determined by a fixed effects model. The mean effect size can then be taken as an estimate for the effect size in the population. However, if the fixed effects model results in significant homogeneity statistics, the data have to be analyzed using a random effects model (Hunter \& Schmidt, 2004). In this case, we will report effect size statistics as determined by a random effects model.

In the moderator analyses, we then analyzed the influence of sample characteristics as potential moderators of effect size. In multiple regression analysis, only continuous or dichotomous predictors can be used. Therefore, we transformed the categorical variable type of event into a dichotomous variable contrasting samples with military war experience and samples with other types of events. We decided to focus on this contrast because this distinction is frequently discussed in the literature on anger and PTSD (cf. Novaco \& Chemtob, 1998). Subsequently, in an analysis of variance, we will investigate the influence of type of event in more detail using all of the original categories.

\section{Results}

\section{Description of Studies}


The 39 studies included in the meta-analysis were published between 1985 and 2003, with the median in 2000. Twenty-four studies were conducted in the USA, 9 in Europe, 2 in Israel, 1 in Australia, 1 in Canada, 1 in South Africa, and 1 in Sri Lanka. Sample sizes varied between 20 and 1,698 $(M=226.1, S D=366.1, M d n=94.0)$. The average mean age of participants was 42.8 years $(S D=10.6)$ and the average proportion of female participants was $30 \%$. Nineteen studies reported on military war experience, 7 on criminal victimization, 5 on civilian war experience, 4 on technological disasters, 2 on health traumas, and 2 on samples with mixed events. The average mean time since event varied between 0.03 and 47.50 years $(M=12.4, S D=12.2, M d n=9.0)$.

A wide variety of measures were used in the studies. Anger $(k=29)$ was assessed by the STAXI (Spielberger et al., 1999) in 14 studies, by the Multidimensional Anger Inventory (MAI; Siegel, 1986) in 2 studies, and by other measures in 13 studies. Anger out $(k=8)$ was assessed by the STAXI in 6 studies and by the MAI in 2 studies. Anger in $(k=9)$ was assessed by the STAXI in 7 studies and by the MAI in 2 studies. Anger control $(k=6)$ was exclusively assessed by the STAXI. Hostility $(k=16)$ was assessed by the BDHI (Buss \& Durkee, 1957) in 4 studies, by the SCL-90 (Derogatis et al., 1973; Derogatis \& Savitz, 1999) in 3 studies, by the Cook-Medley Hostility Inventory (Cook \& Medley, 1954) in 2 studies, and by other measures in 7 studies. PTSD $(k=39)$ was assessed by assignment of a PTSD diagnosis in 18 studies and by measures of symptom severity in 21 studies (e.g., PTSD Symptom Scale, Foa, Riggs, Dancu, \& Rothbaum, 1993, in 5 studies; Mississippi Scale for Combat-Related Posttraumatic Stress Disorder, Keane, Caddell, \& Taylor, 1988, in 5 studies; Impact of Event-Scale, Horowitz, Wilner, \& Alvarez, 1979, in 3 studies; and by a range of other measures in 8 studies).

\section{Preliminary Analyses}

First, the data revealed that there are no statistical outliers on effect size variables. We therefore used the complete data set for the subsequent analyses. 
Second, the data showed that it is empirically justified to combine the effect sizes for anger and hostility. There were eight studies providing effect sizes for both anger and hostility. The effect sizes were correlated with $r=.75(p=.031)$. In these studies, the weighted mean effect size was $r=.55$ for anger and $r=.58$ for hostility; the confidence intervals showed that the difference was not significant. Given these results, we computed an effect size for anger/hostility combined (with $k=37$ ) and used this effect size in the analysis of publication bias and in the moderator analyses. The fact that the effect sizes for anger and hostility did not significantly differ, however, does not mean that the distinction between anger and hostility is not meaningful. The result may be traced back to both conceptual links and imprecise measurement of anger and hostility, as discussed in the introduction section.

Third, the data revealed strong evidence against a publication bias. A funnel graph showed that studies with small sample size did not show a bias towards larger effect sizes (Figure 1). The distribution of effect sizes exhibits a symmetric shape typical of non-biased meta-analytic data sets, which led to the decision not to include dissertations and unpublished reports in our meta-analysis. In addition, we computed the file drawer statistic (Rosenthal, 1979). The results showed that 86 unpublished studies with null effects were needed to produce a non-significant overall effect size for anger/hostility. We judged that it is unlikely that so many unpublished studies on anger, hostility, and PTSD with null effects exist.

\section{Effect Size Analyses}

Weighted mean effect sizes were computed for anger, anger out, anger in, anger control, hostility, and anger/hostility. First, we computed effect size statistics for both a fixed effects model and a random effects model. For all effect size variables, the homogeneity statistics were significant, indicating that the variance of effect sizes cannot be attributed to within-study 
sampling error only, but also to between-study sampling error. Therefore, in the following, we report the effect size statistics based on a random effects model.

For all effect size variables, Table 1 shows the number of studies $k$, the population size, the weighted mean effect size $r$, the corresponding confidence interval for the weighted mean effect size $r$, and the homogeneity $Q$ with its level of significance. The mean effect size for anger amounts to $r=.48$, the mean effect size for hostility to $r=.53$, and the mean effect size for anger/hostility combined to $r=.48$. Effect sizes for anger and hostility are based on sufficiently large numbers of studies, leading to relatively small confidence intervals. In contrast, the mean effect sizes for anger out, anger in, and anger control are based on relatively small numbers of studies; in consequence, confidence intervals are substantially larger for these effect size variables. The mean effect size for anger out amounts to $r=.29$, the mean effect size for anger in to $r=.53$, and the mean effect size for anger control to $r=-.44$.

\section{Moderator Analyses}

The above analyses revealed heterogeneity of effect size variances; therefore, it was essential to investigate whether moderator variables explain variation of effect sizes. We restricted the moderator analyses to the effect size for anger/hostility combined because this effect size variable was based on the largest number of studies $(k=37)$. Because the number of studies determines the power of the moderator tests, we judged the number of studies to be too small to conduct moderator analyses for the other effect size variables.

First, we tested whether the mean time since event is a better predictor if the variable is used in its original linear metric or in a logarithmic metric. Therefore, we computed a linear model and logarithmic model for the simple regression of effect size on mean time since event. The linear model was not significant, with $F=0.53, d f=31$, and $p=.470$. In contrast, the logarithmic model was significant, with $F=7.52, d f=31$, and $p=.010$. Therefore, we decided to 
use mean time since event in its logarithmic metric in the further analyses. Figure 2 illustrates the logarithmic relation between the effect size for anger/hostility and mean time since event; for reasons of illustration the figure shows the $r$-values of effect size, but the computations were made using Fisher's $Z_{r}$ transformed values of $r$. The corresponding logarithmic regression equation is: $Z_{r}=0.494+0.046 * \ln$ (time).

We next computed simple correlations for the effect size for anger/hostility and sample characteristics (Table 2). The results show that type of event and mean time since event were substantially correlated with effect size. The mean age of participants was virtually uncorrelated with effect size. The proportion of female participants in the sample correlated with effect size at a medium height, though not significantly due to low statistical power. To control for potential multicollinearity of the predictors, we computed a multiple regression analysis with sample characteristics as predictors of effect size for anger/hostility (Table 2). Overall, the variance explained by sample characteristics amounts to $R^{2}=.38$. The results show that both type of event and mean time since event are important predictors with regression coefficients of .42 and .47 , respectively, even if the regression coefficient of type of event is not statistically significant due to low statistical power. The predictors mean age of participants and proportion of female participants did not show regression coefficients with substantial weight.

Finally, because type of event was only used as a dichotomous variable in the preceding analyses, we computed an analysis of variance to investigate the influence of type of event on effect size for anger/hostility in more detail (Table 3). The results corroborate the importance of type of event as a predictor of effect size, as the mean effect sizes substantially differ between the categories.

\section{Discussion}


The results of this meta-analysis show that anger and hostility are substantially associated with PTSD among trauma-exposed adults. Overall, 39 studies were included in the meta-analysis. Effect sizes did not significantly differ for anger and hostility and we therefore determined the mean effect size on an aggregate level combining the results for anger and hostility. The weighted mean effect size for anger/hostility combined was $r=.48$, indicating a large effect (Cohen, 1992). The studies included in the analysis differed substantially with respect to sample characteristics like type of traumatic event, time since event, mean age of participants, proportion of female participants, and country of origin. Moreover, the studies used a variety of measures to assess anger, hostility, and PTSD. The heterogeneity of sample characteristics and methodological characteristics strengthens the generalizability of the results.

The weighted mean effect sizes for the relation between anger expression variables and PTSD were $r=.29$ for anger out, $r=.53$ for anger in, and $r=-.44$ for anger control. Thus, the correlation between anger out and PTSD corresponds to a medium effect and is considerably lower than the correlation between anger in and PTSD, which corresponds to a large effect (Cohen, 1992). Anger in measures the frequency of inhibition and non-disclosure of anger; an inspection of the STAXI (Spielberger et al., 1999) and MAI (Siegel, 1986) items suggests that the anger in scales also measure anger rumination. A ruminative style of emotion regulation might be closely linked to the re-experiencing symptom cluster in PTSD (e.g., Ehlers et al., 1998), which might explain the strong correlation between anger in and PTSD. In contrast, an expressive style of emotion regulation, as comprised in measures of anger out, is not part of the characteristic posttraumatic stress reactions, explaining the lower correlation between anger out and PTSD. Finally, the correlation between anger control and PTSD corresponds to a large negative effect. It is possible that strong posttraumatic stress reactions reduce the ability of an individual to control anger by decreasing mental resources. 
The analyses showed that the distribution of effect sizes was not homogeneous; therefore, we conducted moderator analyses of the effect size for anger/hostility which revealed that mean time since event and type of event are sample characteristics that explain substantial proportions of variance in effect size with beta $=.47$ and beta $=.42$, respectively. In contrast, the mean age of participants and proportion of female participants did not significantly contribute to the prediction of effect size in the multiple regression analysis.

Time since the event was, as expected, a significant predictor in a logarithmically transformed metric but not in a linear metric. Thus, the relation between time since event and effect size should be modeled as follows: immediately after a traumatic event, the strength of association between anger and PTSD, and hostility and PTSD respectively, is low. In the first months, the strength of association increases strongly. Thereafter, the slope of the curve continuously decreases so that the curve begins to converge to a limiting value. Of course a logarithmic curve does not converge to a limiting value; however, with increasing time since event the slope of the curve decreases to a value that is, with respect to the purpose of the model, close enough to zero.

Type of event proved to be a second moderator of the association. In samples with military war experience the effect size was higher $(r=.56)$ than in samples with other types of event. We determined the lowest effect size for victims of criminal victimization $(r=.30)$. For all other types of event the effect sizes ranged between $r=.43$ and $r=.48$. But does the high effect size for samples with military war experience really reflect a higher impact of military traumatic events on the relation between anger, hostility, and PTSD? Or are there methodological factors that might explain the finding? One factor might be that individuals with military war experience are preselected by the military administration. Presumably, individuals selected for military service differ from the general population on relevant traits, e.g., they might have higher 
assertiveness, aggressiveness, and trait anger. We can only speculate whether higher pre-event trait anger leads to a stronger post-event association between anger and PTSD or not, because the psychological processes accounting for the association are still disputable. However, it is possible that it is not the type of event that causes the stronger association, but that the pre-event selection accounts for the larger effect size in samples with military war experience. Thus, the metaanalysis does not supply evidence for a causal influence of this moderating factor. Moreover, we would like to emphasize that the results of the meta-analysis show that anger and hostility are substantially related to PTSD among samples with all possible types of traumatic events, not only in individuals with combat-related PTSD.

A first crucial goal in future research on anger, hostility, and PTSD is to investigate the causality of the relationship. Is anger and hostility a causal factor maintaining PTSD? Or is increased anger and hostility a causal effect of strong posttraumatic stress reactions? To study the causality of the relation between anger, hostility, and PTSD, longitudinal data sets with multiple repeated measures are necessary. A recent study suggests that PTSD has a causal effect on anger, but that anger has no causal effect on PTSD (Orth et al., submitted). Further studies should investigate the causal processes using other samples and other measures of anger, hostility, and PTSD.

A second crucial goal in future research should be to conduct more rigorous tests of theories that might explain the relation of anger and PTSD. In these tests, potential mediator variables (e.g., fear avoidance motivation) should be investigated so that the fit of alternative plausible models can be compared. Moreover, the symptom clusters of PTSD (re-experiencing, avoidance, hyperarousal) should be included, so that differing mediator models can be tested: for example, the hyperarousal cluster of PTSD might be a possible causal factor of the relationship, linking PTSD and anger by the physiological pathway. Indeed, the hyperarousal cluster has 
recently been shown to have a substantial and mainly unidirectional causal effect on the other PTSD symptom clusters (Schell, Marshall, \& Jaycox, 2004). In addition, anger variables should be assessed with more precision. It might be crucial whether the relation between anger and PTSD can be traced back to increased trauma-related anger (e.g., anger against the perpetrator or against individuals who did not prevent the occurrence of the traumatic event) or to increased non-trauma-related anger (e.g., anger at the work place or in the family). Finally, future studies should test further potential moderator variables of the relation between anger and PTSD (e.g., social support).

Knowledge about causality and the psychological processes that account for the association may help to design more efficient treatment strategies of PTSD and more efficient anger management interventions. Anger-specific treatment is not only necessary if anger has a causal effect on PTSD; effective treatment and prevention of chronic anger and hostility among traumatized individuals is required because anger and hostility is a severe problem for the individual, reducing subjective well-being and social functioning. Moreover, chronic anger and hostility among traumatized individuals is also a severe problem for society because anger and hostility might drive the cycle of violence, and traumatized individuals might themselves become perpetrators of aggression and violence (e.g., Beckham et al., 1997; Beckham, Moore, \& Reynolds, 2000). Fortunately, the necessity of treatment for anger in PTSD has already been recognized and treatment strategies have already been developed (e.g., Chemtob, Novaco, Hamada, \& Gross, 1997). 


\section{References}

References marked with an asterisk indicate studies included in the meta-analysis.

*Abe, J., Zane, N., \& Chun, K. (1994). Differential responses to trauma: Migration-related discriminants of post-traumatic stress disorder among Southeast Asian refugees. Journal of Community Psychology, 22, 121-135.

American Psychiatric Association. (1987). Diagnostic and statistical manual of mental disorders: DSM-III-R. Washington, DC: Author.

American Psychiatric Association. (1994). Diagnostic and statistical manual of mental disorders: $D S M-I V$. Washington, DC: Author.

*Andrews, B., Brewin, C. R., Rose, S., \& Kirk, M. (2000). Predicting PTSD symptoms in victims of violent crime: The role of shame, anger, and childhood abuse. Journal of Abnormal Psychology, 109, 69-73.

*Bean, J., \& Möller, A. T. (2002). Posttraumatic stress and depressive symptomatology in a sample of battered women from South Africa. Psychological Reports, 90, 750-752.

Beckham, J. C., Feldman, M. E., Kirby, A. C., Hertzberg, M. A., \& Moore, S. D. (1997). Interpersonal violence and its correlates in Vietnam veterans with chronic posttraumatic stress disorder. Journal of Clinical Psychology, 53, 859-869.

Beckham, J. C., Moore, S. D., \& Reynolds, V. (2000). Interpersonal hostility and violence in Vietnam combat veterans with chronic posttraumatic stress disorder: A review of theoretical models and empirical evidence. Aggression and Violent Behavior, 5, 451-466.

Beckham, J. C., Roodman, A. A., Barefoot, J. C., Haney, T. L., Helms, M. J., Fairbank, J. A., Hertzberg, M. A., \& Kudler, H. S. (1996). Interpersonal and self-reported hostility among combat veterans with and without posttraumatic stress disorder. Journal of Traumatic Stress, 9, 335-342. 
Beckham, J. C., Vrana, S. R., Barefoot, J. C., Feldman, M. E., Fairbank, J., \& Moore, S. D. (2002). Magnitude and duration of cardiovascular responses to anger in Vietnam veterans with and without posttraumatic stress disorder. Journal of Consulting and Clinical Psychology, 70, 228-234.

Begg, C. B. (1994). Publication bias. In H. Cooper \& L. V. Hedges (Eds.), The handbook of research synthesis (pp. 399-409). New York: Russell Sage Foundation.

Berkowitz, L. (1999). Anger. In T. Dalgleish \& M. J. Power (Eds.), Handbook of cognition and emotion (pp. 411-428). Chichester: Wiley.

Bower, G. H. (1981). Mood and memory. American Psychologist, 36, 129-148.

*Bramsen, I., van der Ploeg, H. M., van der Kamp, L. J. T., \& Ader, H. J. (2002). Exposure to traumatic war events and neuroticism: The mediating role of attributing meaning. Personality and Individual Differences, 32, 747-760.

Brewin, C. R., \& Holmes, E. A. (2003). Psychological theories of posttraumatic stress disorder. Clinical Psychology Review, 23, 339-376.

Buss, A. H., \& Durkee, A. (1957). An inventory for assessing different kinds of hostility. Journal of Consulting Psychology, 21, 343-349.

Buss, A. H., \& Perry, M. (1992). The aggression questionnaire. Journal of Personality and Social Psychology, 63, 452-459.

*Butterfield, M. I., Forneris, C. A., Feldman, M. E., \& Beckham, J. C. (2000). Hostility and functional health status in women veterans with and without posttraumatic stress disorder: A preliminary study. Journal of Traumatic Stress, 13, 735-741.

*Cahill, S. P., Rauch, S. A., Hembree, E. A., \& Foa, E. B. (2003). Effect of cognitive-behavioral treatments for PTSD on anger. Journal of Cognitive Psychotherapy, 17, 113-131. 
Calhoun, P. S., Beckham, J. C., \& Bosworth, H. B. (2002). Caregiver burden and psychological distress in partners of veterans with chronic posttraumatic stress disorder. Journal of Traumatic Stress, 15, 205-212.

*Calhoun, P. S., Beckham, J. C., Feldman, M. E., Barefoot, J. C., Haney, T., \& Bosworth, H. B. (2002). Partners' ratings of combat veterans' anger. Journal of Traumatic Stress, 15, 133136.

*Carroll, E. M., Rueger, D. B., Foy, D. W., \& Donahoe, C. P. (1985). Vietnam combat veterans with posttraumatic stress disorder: Analysis of marital and cohabitating adjustment. Journal of Abnormal Psychology, 94, 329-337.

*Chemtob, C. M., Hamada, R. S., Roitblat, H. L., \& Muraoka, M. Y. (1994). Anger, impulsivity, and anger control in combat-related posttraumatic stress disorder. Journal of Consulting and Clinical Psychology, 62, 827-832.

Chemtob, C. M., Novaco, R. W., Hamada, R. S., \& Gross, D. M. (1997). Cognitive-behavioral treatment for severe anger in posttraumatic stress disorder. Journal of Consulting and Clinical Psychology, 65, 184-189.

Chemtob, C. M., Novaco, R. W., Hamada, R. S., Gross, D. M., \& Smith, G. (1997). Anger regulation deficits in combat-related posttraumatic stress disorder. Journal of Traumatic Stress, 10, 17-36.

*Chibnall, J. T., \& Duckro, P. N. (1994). Post-traumatic stress disorder in chronic post-traumatic headache patients. Headache, 34, 357-361.

Cohen, J. (1992). A power primer. Psychological Bulletin, 112, 155-159.

Cole, D. A., \& Maxwell, S. E. (2003). Testing mediational models with longitudinal data: Questions and tips in the use of structural equation modeling. Journal of Abnormal Psychology, 112, 558-577. 
Cook, W. W., \& Medley, D. M. (1954). Proposed hostility and pharisaic-virtue scales for the MMPI. Journal of Applied Psychology, 38, 414-418.

*Crowson, J. J., Frueh, B. C., \& Snyder, C. R. (2001). Hostility and hope in combat-related Posttraumatic Stress Disorder: A look back at combat as compared to today. Cognitive Therapy and Research, 25, 149-165.

*Deimling, G. T., Kahana, B., Bowman, K. F., \& Schaefer, M. L. (2002). Cancer survivorship and psychological distress in later life. Psycho-Oncology, 11, 479-494.

Derogatis, L. R., Lipman, R. S., \& Covi, L. (1973). SCL-90: An outpatient psychiatric rating scale--preliminary report. Psychopharmacology Bulletin, 9, 13-28.

Derogatis, L. R., \& Savitz, K. L. (1999). The SCL-90-R, Brief Symptom Inventory, and matching clinical rating scales. In M. E. Maruish (Ed.), The use of psychological testing for treatment planning and outcomes assessment (pp. 679-724). Mahwah, NJ: Erlbaum.

*Doerfler, L. A., Pbert, L., \& DeCosimo, D. (1994). Symptoms of posttraumatic stress disorder following myocardial infarction and coronary artery bypass surgery. General Hospital Psychiatry, 16, 193-199.

Eckhardt, C., Norlander, B., \& Deffenbacher, J. (2004). The assessment of anger and hostility: A critical review. Aggression and Violent Behavior, 9, 17-43.

*Ehlers, A., Mayou, R. A., \& Bryant, B. (1998). Psychological predictors of chronic posttraumatic stress disorder after motor vehicle accidents. Journal of Abnormal Psychology, 107, 508-519.

*Ekblad, S., Prochazka, H., \& Roth, G. (2002). Psychological impact of torture: A 3-month follow-up of mass-evacuated Kosovan adults in Sweden. Lessons learnt for prevention. Acta Psychiatrica Scandinavica, 106, 30-36. 
*Feeny, N. C., Zoellner, L. A., \& Foa, E. B. (2000). Anger, dissociation, and posttraumatic stress disorder among female assault victims. Journal of Traumatic Stress, 13, 89-100.

Foa, E. B., Riggs, D. S., Dancu, C. V., \& Rothbaum, B. O. (1993). Reliability and validity of a brief instrument for assessing post-traumatic stress disorder. Journal of Traumatic Stress, $6,459-473$.

Foa, E. B., Riggs, D. S., Masie, E. D., \& Yarczower, M. (1995). The impact of fear activation and anger on the efficacy of exposure treatment for posttraumatic stress disorder. Behavior Therapy, 26, 487-499.

*Forbes, D., Creamer, M., Hawthorne, G., Allen, N., \& McHugh, T. (2003). Comorbidity as a predictor of symptom change after treatment in combat-related posttraumatic stress disorder. Journal of Nervous and Mental Disease, 191, 93-99.

Ford, J. D., Fisher, P., \& Larson, L. (1997). Object relations as a predictor of treatment outcome with chronic posttraumatic stress disorder. Journal of Consulting and Clinical Psychology, 65, 547-559.

*Freed, D., Bowler, R., \& Fleming, I. (1998). Post-traumatic stress disorder as a consequence of a toxic spill in northern California. Journal of Applied Social Psychology, 28, 264-281.

*Frueh, B. C., Henning, K. R., Pellegrin, K. L., \& Chobot, K. (1997). Relationship between scores on anger measures and PTSD symptomatology, employment, and compensationseeking status in combat veterans. Journal of Clinical Psychology, 53, 871-878.

Horowitz, M. J., Wilner, N., \& Alvarez, W. (1979). Impact of Event Scale: A measure of subjective stress. Psychosomatic Medicine, 41, 209-218.

*Hovens, J. E., Bramsen, I., \& van der Ploeg, H. M. (2002). Self-rating inventory for posttraumatic stress disorder: Review of the psychometric properties of a new brief Dutch screening instrument. Perceptual and Motor Skills, 94, 996-1008. 
*Hovens, J. E., Op den Velde, W., Falger, P. R., Schouten, E. G., De Groen, J. H. M., \& Van Duijn, H. (1992). Anxiety, depression and anger in Dutch Resistance veterans from World War II. Psychotherapy and Psychosomatics, 57, 172-179.

Hunter, J. E., \& Schmidt, F. L. (2004). Methods of meta-analysis: Correcting error and bias in research findings. Thousand Oaks, CA: Sage.

Hyer, L., O'Leary, W. C., Saucer, R. T., Blount, J., Harrison, W. R., \& Boudewyns, P. A. (1986). Inpatient diagnosis of posttraumatic stress disorder. Journal of Consulting and Clinical Psychology, 54, 698-702.

Izard, C. E. (1991). The psychology of emotions. New York: Plenum.

Keane, T. M., Caddell, J. M., \& Taylor, K. L. (1988). Mississippi Scale for Combat-Related Posttraumatic Stress Disorder: Three studies in reliability and validity. Journal of Consulting and Clinical Psychology, 56, 85-90.

*Koenen, K. C., Stellman, J. M., Stellman, S. D., \& Sommer, J. F. (2003). Risk factors for course of posttraumatic stress disorder among Vietnam veterans: A 14-year follow-up of American legionnaires. Journal of Consulting and Clinical Psychology, 71, 980-986.

*Kubany, E. S., Leisen, M. B., Kaplan, A. S., \& Kelly, M. P. (2000). Validation of a brief measure of posttraumatic stress disorder: The Distressing Event Questionnaire (DEQ). Psychological Assessment, 12, 197-209.

*Laor, N., Wolmer, L., Wiener, Z., Weizman, R., Toren, P., \& Ron, S. (1999). Image control and symptom expression in posttraumatic stress disorder. Journal of Nervous and Mental Disease, 187, 673-679.

*Lasko, N. B., Gurvits, T. V., Kuhne, A. A., Orr, S. P., \& Pitman, R. K. (1994). Aggression and its correlates in Vietnam veterans with and without chronic posttraumatic stress disorder. Comprehensive Psychiatry, 35, 373-381. 
Lipsey, M. W., \& Wilson, D. B. (2001). Practical meta-analysis. Thousand Oaks, CA: Sage.

Mayou, R. A., Ehlers, A., \& Bryant, B. (2002). Posttraumatic stress disorder after motor vehicle accidents: 3-year follow-up of a prospective longitudinal study. Behaviour Research and Therapy, 40, 665-675.

*McFall, M. E., Smith, D. E., Mackay, P. W., \& Tarver, D. J. (1990). Reliability and validity of Mississippi Scale for combat-related posttraumatic stress disorder. Psychological Assessment, 2, 114-121.

*McFall, M. E., Wright, P. W., Donovan, D. M., \& Raskind, M. (1999). Multidimensional assessment of anger in Vietnam veterans with posttraumatic stress disorder. Comprehensive Psychiatry, 40, 216-220.

Miller, T. Q., Smith, T. W., Turner, C. W., Guijarro, M. L., \& Hallet, A. J. (1996). A metaanalytic review of research on hostility and physical health. Psychological Bulletin, 119, $322-348$.

*Morgan, T., \& Cummings, A. L. (1999). Change experienced during group therapy by female survivors of childhood sexual abuse. Journal of Consulting and Clinical Psychology, 67, 28-36.

Novaco, R. W., \& Chemtob, C. M. (1998). Anger and trauma: Conceptualization, assessment, and treatment. In V. M. Follette \& J. I. Ruzek \& F. R. Abueg (Eds.), Cognitive-behavioral therapies for trauma (pp. 162-190). New York: Guilford.

*Novaco, R. W., \& Chemtob, C. M. (2002). Anger and combat-related posttraumatic stress disorder. Journal of Traumatic Stress, 15, 123-132.

Orth, U., Cahill, S. P., Foa, E. B., \& Maercker, A. (submitted). Anger and posttraumatic stress disorder: A causal analysis with longitudinal data. 
*Pitman, R. K., Orr, S. P., Forgue, D. F., de Jong, J. B., \& Claiborn, J. M. (1987).

Psychophysiological assessment of posttraumatic stress disorder imagery in Vietnam combat veterans. Archives of General Psychiatry, 44, 970-975.

Riggs, D. S., Dancu, C. V., Gershuny, B. S., Greenberg, D., \& Foa, E. B. (1992). Anger and posttraumatic stress disorder in female crime victims. Journal of Traumatic Stress, 5, 613625.

Roberts, W. R., Penk, W. E., Gearing, M. L., Robinowitz, R., Dolan, M. P., \& Patterson, E. T. (1982). Interpersonal problems of Vietnam combat veterans with symptoms of posttraumatic stress disorder. Journal of Abnormal Psychology, 91, 444-450.

Rosenthal, R. (1979). The "file drawer problem" and tolerance for null results. Psychological Bulletin, 86, 638-641.

Schafer, J. L., \& Graham, J. W. (2002). Missing data: Our view of the state of the art. Psychological Methods, 7, 147-177.

Schell, T. L., Marshall, G. N., \& Jaycox, L. H. (2004). All symptoms are not created equal: The prominent role of hyperarousal in the natural course of posttraumatic psychological distress. Journal of Abnormal Psychology, 113, 189-197.

*Schützwohl, M., \& Maercker, A. (2000). Anger in former East German political prisoners: Relationship to posttraumatic stress reactions and social support. Journal of Nervous and Mental Disease, 188, 483-489.

Siegel, J. M. (1986). The multidimensional anger inventory. Journal of Personality and Social Psychology, 51, 191-200.

*Solomon, M. J., \& Thompson, J. (1995). Anger and blame in three technological disasters. Stress Medicine, 11, 199-206. 
Solomon, Z. (1989). Characteristic psychiatric symptomatology of post-traumatic stress disorder in veterans: A three year follow-up. Psychological Medicine, 19, 927-936.

*Solomon, Z., Mikulincer, M., \& Bleich, A. (1988). Characteristic expressions of combat-related posttraumatic stress disorder among Israeli soldiers in the 1982 Lebanon war. Behavioral Medicine, 14, 171-178.

*Somasundaram, D. J. (1996). Post-traumatic responses to aerial bombing. Social Science and Medicine, 42, 1465-1471.

Spielberger, C. D., Sydeman, S. J., Owen, A. E., \& Marsh, B. J. (1999). Measuring anxiety and anger with the State-Trait Anxiety Inventory (STAI) and the State-Trait Anger Expression Inventory (STAXI). In M. E. Maruish (Ed.), The use of psychological testing for treatment planning and outcomes assessment (pp. 993-1021). Mahwah, NJ: Erlbaum.

*Stanford, M. S., Vasterling, J. J., Mathias, C. W., Constans, J. I., \& Houston, R. J. (2001). Impact of threat relevance on P3 event-related potentials in combat-related post-traumatic stress disorder. Psychiatry Research, 102, 125-137.

*Sutker, P. B., Corrigan, S. A., Sundgaard-Riise, K., Uddo, M., \& Allain, A. N. (2002). Exposure to war trauma, war-related PTSD, and psychological impact of subsequent hurricane. Journal of Psychopathology and Behavioral Assessment, 24, 25-37.

*Woolfolk, R. L., \& Grady, D. A. (1988). Combat-related posttraumatic stress disorder: Patterns of symptomatology in help-seeking Vietnam veterans. Journal of Nervous and Mental Disease, 176, 107-111.

Zoellner, L. A., Foa, E. B., \& Brigidi, B. D. (1999). Interpersonal friction and PTSD in female victims of sexual and nonsexual assault. Journal of Traumatic Stress, 12, 689-700.

*Zoellner, L. A., Goodwin, M. L., \& Foa, E. B. (2000). PTSD severity and health perceptions in female victims of sexual assault. Journal of Traumatic Stress, 13, 635-649. 


\section{Author Note}

Ulrich Orth and Elias Wieland, Department of Psychology, University of Berne, Switzerland.

Preparation of this paper was supported by Grant 101511-101616 from the Swiss National Science Foundation to Ulrich Orth. We thank Martin Grosse Holtforth for helpful comments on an earlier version of this article.

Correspondence concerning this article should be addressed to Ulrich Orth, Department of Psychology, University of Berne, Muesmattstrasse 45, 3012 Berne, Switzerland. E-mail: ulrich.orth@psy.unibe.ch. 
Table 1

Summary of Effect Sizes

\begin{tabular}{|c|c|c|c|c|c|}
\hline Effect size & $k$ & Population size & $\begin{array}{c}\text { Weighted mean } \\
\text { effect size } r\end{array}$ & $\begin{array}{c}\text { 95\%-CI for weighted } \\
\text { mean effect size } r\end{array}$ & Homogeneity $Q$ \\
\hline Anger & 29 & 7,486 & $.48 * * *$ & $.43 / .53$ & $173.83 * * *$ \\
\hline Anger out & 8 & 600 & $.29 * * *$ & $.09 / .47$ & $42.69 * * *$ \\
\hline Anger in & 9 & 676 & $.53 * * *$ & $.39 / .65$ & $41.88 * * *$ \\
\hline Anger control & 6 & 406 & $-.44 * * *$ & $-.19 /-.63$ & $35.21 * * *$ \\
\hline Hostility & 16 & 1,788 & $.53 * * *$ & $.47 / .59$ & $34.71 * *$ \\
\hline Anger/hostility & 37 & 8,700 & $.48 * * *$ & $.44 / .53$ & $191.41 * * *$ \\
\hline
\end{tabular}

Note. $k=$ number of studies. Computations were made with a random effects model.

$* p<.05 . * * p<.01 . * * * p<.001$ 
Table 2

Correlations and Standardized Regression Coefficients for Sample Characteristics Predicting Effect Size for Anger/Hostility $(\mathrm{k}=32)$

\begin{tabular}{lcc}
\hline \multicolumn{1}{c}{ Predictors } & $r$ & beta \\
\hline Mean age & .07 & -.13 \\
Proportion of female participants & -.34 & .14 \\
Type of event ${ }^{\mathrm{a}}$ & $.48^{* *}$ & .42 \\
Mean time since event $(\log )$ & $.49^{* *}$ & $.47^{*}$
\end{tabular}

Note. $k=$ number of studies. $\log =$ logarithmically transformed variable. Computations for the multiple regression analysis were made with a random effects model (full-information maximum likelihood). Homogeneity $Q_{\text {Model }}=21.17(d f=4, p=.000)$, Homogeneity $Q_{\text {Residual }}=34.01(d f=$ $27, p=.166) . R^{2}=.38$.

${ }^{\mathrm{a}} 1=$ military war experience, $0=$ other.

$* p<.05 . * * p<.01 . * * * p<.001$. 
Table 3

Analysis of Variance of Effect Size for Anger/Hostility by Event Type $(k=37)$

\begin{tabular}{|c|c|c|c|c|c|}
\hline Event type & $k$ & Population size & $\begin{array}{c}\text { Weighted mean } \\
\text { effect size } r\end{array}$ & $\begin{array}{c}\text { 95\%-CI for weighted } \\
\text { mean effect size } r\end{array}$ & Homogeneity $Q$ \\
\hline Military war experience & 19 & 5,367 & $.56 * * *$ & $.51 / .60$ & 17.57 \\
\hline Criminal victimization & 6 & 575 & $.30 * * *$ & $.17 / .41$ & 8.56 \\
\hline Civilian war experience & 5 & 789 & $.43 * * *$ & $.31 / .54$ & 6.32 \\
\hline Technological disaster & 3 & 1,459 & $.48 * * *$ & $.36 / .59$ & $6.50 *$ \\
\hline Health trauma & 2 & 230 & $.44 * * *$ & $.25 / .60$ & 0.47 \\
\hline Mixed & 2 & 398 & $.37 * * *$ & $.19 / .52$ & 1.07 \\
\hline
\end{tabular}

Note. $k=$ number of studies. Computations were made with a random effects model (full-information maximum likelihood).

Homogeneity $Q_{\text {Between }}=21.31(d f=5, p=.001)$, Homogeneity $Q_{\text {Within }}=40.50(d f=31, p=.118)$.

$* p<.05 . * * p<.01 . * * * p<.001$ 


\section{Figure Captions}

Figure 1. Funnel graph displaying the relation between the effect size $r$ for anger/hostility and sample size of the studies.

Figure 2. Scatterplot displaying the logarithmic relation between the effect size $r$ for anger/hostility and mean time since event. 


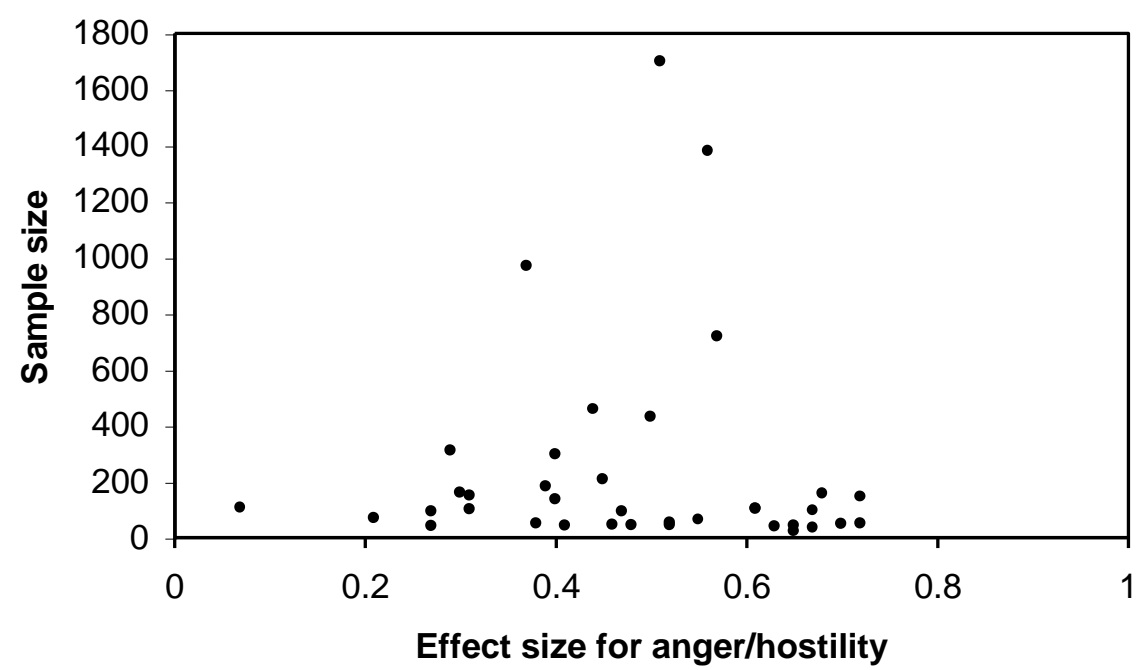




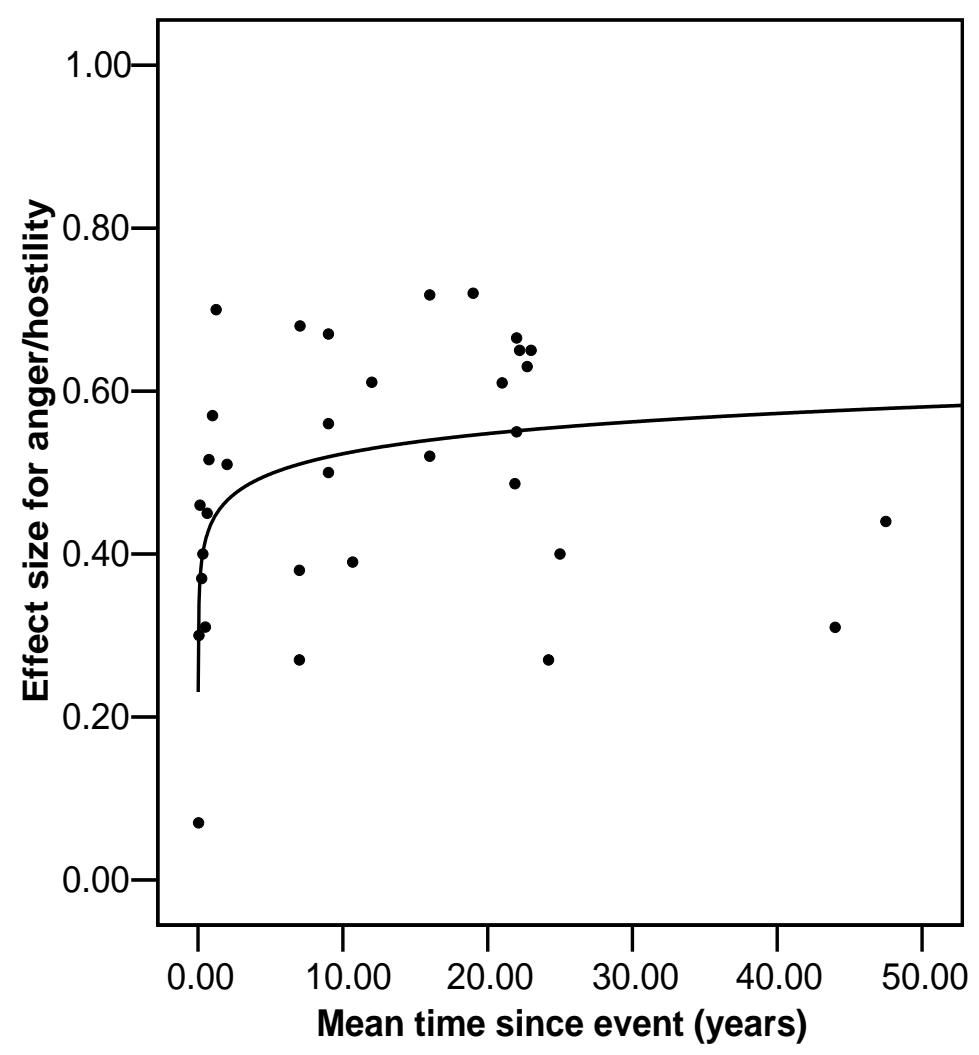

